JURNAL KEBIDANAN

Vol 6, No 4, Oktober 2020 : 453-461

\title{
HUBUNGAN PENGETAHUAN, SIKAP, DAN PERILAKU TOKOH MASYARAKAT DENGAN STRATA POSYANDU
}

\author{
Rizsa Uswah Rofiqoh ${ }^{1}$, Didah $^{2}$, Ardini Raksanagara ${ }^{3}$ \\ 1,2Program Diploma Kebidanan, Fakultas Kedokteran Universitas Padjadjaran \\ 1email: rizsauswah@gmail.com \\ 2email: didahramdani@gmail.com \\ 3 Departemen IImu Kesehatan Masyarakat Fakultas Kedokteran Universitas Padjadjaran \\ 3email: ardiniraksanagara@gmail.com
}

\begin{abstract}
Background: The Posyandu (Integrated Service Post) in to improve the society's domestic health independently. In Indonesia the number of Pratama Health Service Posts is large and in Sumedang, West Java, the number of Pratama Health Service Posts (Posyandu Pratama) is larger compared to independent Health Service Posts (Posyandu mandiri). To improve the level of Posyandu to become independent, supports from the community leaders who have knowledge regarding the importance of Posyandu are required, so that the community leaders possess the demeanor and behavior to participate in the Posyandu within their area. Community leaders play a very important role in increasing public awareness about health that is obtained from posyandu services. The independent strata posyandu that is expected by all regions, because it reflects the high level of independent health awareness in the community.

Purpose: Knowing of correlation between knowledge, demeanor, and behavior of community leaders with the Posyandu Strata.

Methods: This research used a descriptive analytical design method with a cross-sectional approach. The sample was Community Leaders in the work area of Jatinangor Health Center. The research was conducted on June-July 2018. Sampling technique used was proportional stratified random sampling with a sample of 78 participants. The data source employed is primary data obtained from the results of the questionnaire.Data analysis used was Gamma Test.

Results: Showed that the majority of participants had enough knowledge 49 participants $(62,8 \%)$, had negative attitude 46 participants (59,0\%), and had unsupporting behaviors 48 participants $(61,5 \%)$. There is a significant relationship between knowledge, attitudes, and behavior of community leaders about Posyandu with Posyandu Strata was shown in $p=0,000$.

Conclusion: Based on the results of the study, it can be concluded that there is a relationship between knowledge, attitudes, and behavior of community leaders about the Posyandu with Posyandu Strata.

Suggestion: It is hoped that the Puskesmas will be able to provide training on the role of community leaders in posyandu to increase the knowledge and awareness of community leaders regarding their role in posyandu.
\end{abstract}

Keywords: Knowledge, Attitudes, Behaviors, Posyandu, Community Leaders

\section{ABSTRAK}

Latar Belakang: Posyandu bertujuan untuk membantu masyarakat meningkatkan kesehatan keluarga secara mandiri. Strata Posyandu di Indonesia tertinggi adalah Posyandu Pratama dan di kabupaten Sumedang Jawa Barat posyandu pratama lebih banyak daripada strata posyandu mandiri. Untuk meningkatkan strata posyandu menjadi mandiri diperlukan adanya dukungan tokoh masyarakat yang memiliki pengetahuan tentang pentingnya keberadaan posyandu, agar tokoh masyarakat memiliki sikap dan perilaku untuk berpartisipasi dalam keberadaan posyandu di wilayahnya. Tokoh masyarakat sangat berperan dalam meningkatkan kesadaran masyarakatnya mengenai kesehatan yang didapat dari pelayanan posyandu. Posyandu strata mandiri yang diharapkan oleh semua wilayah, karena mencerminkan tingkat kesadaran kesehatan secara mandiri yang tinggi pada masyarakat.

Tujuan: Mengetahui hubungan pengetahuan, sikap, dan perilaku tokoh masyarakat dengan strata posyandu. 
Metode: Penelitian ini menggunakan metode deskriptif analitik dengan pendekatan cross-sectional. Sampel penelitian adalah Tokoh Masyarakat di wilayah kerja Puskesmas Jatinangor. Penelitian dilakukan pada bulan JuniJuli 2018. Pengambilan sampel menggunakan teknik proportional stratified random sampling dengan jumlah sampel 78 responden. Sumber data yang digunakan adalah. Analisis data menggunakan Uji Korelasi Gamma.

Hasil: Penelitian menunjukan bahwa responden terbanyak berusia 20-49 tahun, bekerja dan berpendidikan terakhir SMA. Responden paling banyak memiliki pengetahuan cukup 49 responden, bersikap positif 45 responden, dan berperilaku tidak mendukung 44 responden. Hasil penelitian menunjukan bahwa terdapat hubungan yang signifikan antara pengetahuan, sikap, dan perilaku tokoh masyarakat dengan strata posyandu bernilai $p=0,000$.

Kesimpulan: Berdasarkan hasil penelitian ini dapat disimpulkan bahwa terdapat hubungan yang signifikan antara pengetahuan, sikap dan perilaku tokoh masyarakat dengan strata posyandu.

Saran: Diharapkan pihak Puskesmas dapat memberikan pelatihan mengenai peran tokoh masyarakat terhadap posyandu dapat meningkatkan pengetahuan dan kesadaran tokoh masyarakat mengenai perannya terhadap posyandu.

Kata Kunci: Pengetahuan, Sikap, Perilaku, Posyandu, Tokoh Masyarakat

\section{PENDAHULUAN}

Posyandu bertujuan agar dapat mewujudkan derajat kesehatan masyarakat yang optimal, salah satu program kesehatan pemerintah dengan memberdayakan masyarakat (Kemenkes RI, 2014). Posyandu dikelola dan diselenggarakan dari, oleh, untuk dan bersama masyarakat, sehingga posyandu bukan hanya tanggung jawab pemerintah saja namun juga merupakan tanggung jawab bersama pemerintah dan masyarakat (Kemenkes RI, 2011; Noerjoedianto, Amir, \& Herwansyah, 2013). Tokoh masyarakat merupakan unsur penggerak dalam menggerakan masyarakat agar berperan aktif dalam kegiatan posyandu dengan memotivasi masyarakat untuk datang ke posyandu (Maternity, Putri, \& Aulia, 2017; Sihombing, Kandarina, \& Sumarni, 2015). Sehingga tokoh masyarakat sangat berpengaruh dan ditokohkan oleh masayarakat di lingkungannya (Makhfudli, 2009).

Pengaruh tokoh masyarakat terhadap keberdaan posyandu di lingkungan masyarakat dipengaruhi oleh pengetahuan, sikap, dan perilaku tokoh masyarakat terhadap keberadaan posyandu. Pengetahuan merupakan informasi yang dimiliki oleh seseorang terhadap suatu hal. Pengetahuan menjadi salah satu faktor yang memengaruhi sikap, sikap merupakan respon atau reaksi seseorang terhadap suatu hal atau proses kesadaran yang dapat menentukan tindakan nyata. Pengetahuan dan sikap merupakan salah satu faktor yang memengaruhi perilaku. Perilaku merupakan tindakan atau aktifitas yang dilakukan oleh seseorang terhadap suatu hal (Wawan \& Dewi, 2010).

Pengetahuan yang dimiliki oleh tokoh masyarakat mengenai posyandu dapat memengaruhi sikap yang merupakan respon tokoh masyarakat terhadap keberadaan strata posyandu di lingkungannya. Sikap tokoh masyarakat terhadap posyandu baik itu positif ataupun negatif, dapat memengaruhi sikap yang diberikan masyarakat terhadap posyandu yang ada di lingkungannya. Hal itu di karenakan masyarakat akan mengikuti sikap tokoh masyarakatnya (Bahtiar, 2012).

Sikap tokoh masyarakat terhadap posyandu dapat memengaruhi perilaku tokoh masyarakat terhadap keberadaan posyandu. Perilaku tokoh masyarakat berperan dalam mendukung terjadinya perubahan perilaku masyarakat, sehingga tokoh masyarakat sangat berperan terhadap perilaku masyarakat untuk datang ke posyandu dalam memberikan motivasi langsung kepada masyarakat untuk berpartisipasi dalam kegiatan posyandu (Akbar, Gani, \& Istiaji, 2015). Tokoh masyarakat sangat berperan dalam menggerakan masyarakat agar berpartisipasi dalam penyelenggaraan kegiatan posyandu dengan dukungan tokoh masyarakat dengan pemanfaatan pelayanan posyandu (Darmawan, 2015).

Data Riset Kesehatan Dasar (Riskesdas) tahun 2016 di Indonesia menunjukan bahwa proporsi tertinggi adalah posyandu pratama, dan proporsi terendah adalah posyandu mandiri (Kemenkes RI, 2013). Data Riset Kesehatan Dasar (Riskesdas) tahun 2016 di Jawa Barat menunjukan bahwa di kabupaten Sumedang terdapat 1.636 posyandu, posyandu pratama 98 posyandu, madya 439 posyandu, purnama 812 posyandu, dan mandiri 287 poyandu. Posyandu yang aktif sebanyak 1099 posyandu atau $67,18 \%$ dari jumlah seluruh posyandu yang ada di kabupaten Sumedang (Kemenkes RI, 2016; Kemenkes RI, 2017). Seluruh desa di wilayah Kabupaten Sumedang Provinsi Jawa Barat telah memiliki kader dan tokoh masyarakat yang terlatih dalam membantu kegiatan pelayanan posyandu, hal ini disebabkan karena pemberdayaan masyarakat dibidang kesehatan memerlukan peran serta kader 
dan tokoh masyarakat. Jika dilihat dari data yang ada, maka perlu ditinjau kembali mengenai peningkatan strata posyandu dengan melibatkan tokoh masyarakat dalam pemberdayaan masyarakat.

Berdasarkan pengambilan data pendahuluan, pada tahun 2017 didapatkan data bahwa terdapat 7 desa di wilayah puskesmas Jatinangor yang tediri dari tokoh masyarakat RW sebanyak 91 orang dan RT sebanyak 334 orang. Strata posyandu pratama lebih banyak daripada strata mandiri dari jumlah posyandu yaitu 91 posyandu. Posyandu pratama 34 posyandu, madya 25 posyandu, purnama 28 posyandu, dan mandiri 4 posyandu. Data tersebut menunjukan bahwa tokoh masyarakat yaitu RT dan RW setempat pengetahuan mengenai posyandu masih kurang hanya mengetahui bahwa posyandu akan dilaksanakan rutin 1 bulan sekali oleh kader tetapi RT dan RW tidak mengetahui manfaat posyandu untuk masyarakatnya dan tidak mengetahui fungsi RT dan RW dalam pelaksanaan dan pengelolaan posyandu. Sikap RT dan RW pun menunjukan bahwa respon yang diberikan terhadap posyandu di wilayahnya masih kurang, karena kebanyakan RT dan RW selaku TOMA beranggapan bahwa RT dan RW tidak memiliki kewajiban dalam mengelola posyandu, TOMA tersebut beranggapan bahwa posyandu hanya dikelola oleh kader saja. Berdasarkan penjelasan tersebut, maka peneliti tertarik untuk melakukan penelitian tentang Hubungan Pengetahuan, Sikap, dan Perilaku Tokoh Masyarakat dengan Strata Posyandu di Wilayah Puskesmas Jatinangor Kabupaten Sumedang.

\section{TUJUAN PENELITIAN}

Mengetahui hubungan pengetahuan, sikap dan perilaku tokoh masyarakat dengan strata posyandu di wilayah kerja Puskesmas Jatinangor.

\section{METODOLOGI PENELITIAN}

Penelitian ini dilakukan dengan metode analitik menggunakan pendekatan potong lintang (cross sectional), yakni subjek hanya di wawancara sebanyak satu kali. Populasi dalam penelitian ini adalah tokoh masyarakat yang berada di wilayah Puskesmas Jatinangor. Sampel dalam penelitian ini diambil dengan teknik proportionate stratified random sampling dan simple random sampling. Proportionate stratified random sampling adalah teknik pengambilan sampel dengan menetapkan jumlah populasi pada tiap kelompok atau strata. Sehingga, besar sampel tokoh masyarakatnya adalah 78 orang. Penelitian dilakukan pada bulan Juni-Juli 2018 di 7 desa wilayah kerja Puskesmas
Jatinangor yaitu Cipacing, Sayang, Hegarmanah, Cikeruh, Cibeusi, Cileles, dan Cilayung. Sumber data yang digunakan adalah data primer yang diperoleh dari hasil pengisian kuesioner dan data sekunder berupa data strata posyandu di wilayah puskesmas Jatinangor.

Kriteria inklusi pada penelitian ini adalah tokoh masyarakat yang berdomisili di wilayah Puskesmas Jatinangor, merupakan RT dan RW, bersedia menjadi responden, dan dapat menulis dan membaca. Sedangkan kriteria eksklusi pada penelitian ini adalah tokoh masyarakat yang tidak mengisi kuesioner dengan lengkap, dan tokoh masyarakat yang tidak adapada saat penelitian. Analisis data menggunakan analisis bivariat $\mathrm{Uji}$ Korelasi Gamma.

Penelitian ini telah mendapatkan persetujuan dari Komite Etik Penelitian Kesehatan Universitas Padjadjaran Fakultas Kedokteran, ijin melakukan penelitian dari pihak Kepala Puskesmas Jatinangor, Camat Jatinangor, dan hasil informed consent kesediaan tokoh masyarakat menjadi responden dalam penelitian ini.

\section{HASIL PENELITIAN}

Penelitian ini terdiri dari 78 responden untuk mengetahui hubungan pengetahuan, sikap dan perilaku tokoh masyarakat dengan strata posyandu sesuai dengan desanya. Hasil penelitian tersebut dapat dilihat dari tabel dibawah.

Berdasarkan hasil pengambilan data primer berupa wawancara langsung dengan responden, dalam penelitian ini didapatkan lebih banyak responden yang bekerja yaitu sebanyak 50 responden $(64,1 \%)$, responden paling banyak berpendidikan SMA yaitu 29 responden $(37,2 \%)$ tetapi masih terdapat 16 responden $(20,5 \%)$ yang berpendidikan SD.

Berdasarkan tabel diatas tampak pengetahuan tokoh masyarakat mengenai posyandu yaitu sebanyak 22 orang responden $(28,2 \%)$ memiliki pengetahuan yang baik dari 78 responden, tetapi masih ada tokoh masyarakat yang pengetahuannya kurang yaitu sebanyak 7 orang $(9,0 \%)$. Sikap tokoh masyarakat sebagai responden lebih banyak yang memiliki sikap negatif terhadap posyandu yaitu sebanyak 46 orang $(59,0 \%)$. Berdasarkan tabel tersebut juga nampak bahwa lebih banyak tokoh masyarakat yang menunjukan perilaku tidak mendukung terhadap posyandu yaitu sebanyak 48 responden $(61,5 \%)$.

Tabel 1.

Distribusi Frekuensi Karakteristik Responden

\begin{tabular}{lll} 
Karakteristik Responden & N & $\%$ \\
\hline
\end{tabular}




\begin{tabular}{lcc}
\hline Kelompok Usia & & \\
$20-49$ tahun & 49 & 62,8 \\
$50-64$ tahun & 26 & 33,3 \\
$>64$ tahun & 3 & 3,9 \\
Pekerjaan & & \\
Wiraswasta & 31 & 39,7 \\
Pegawai Swasta & 2 & 2,6 \\
Guru & 2 & 2,6 \\
lbu Rumah Tangga & 28 & 35,9 \\
PNS & 7 & 9,0 \\
Buruh & 8 & 10,2 \\
Pendidikan Terakhir & & \\
SD & 16 & 20,5 \\
SMP & 25 & 32,1 \\
SMA & 29 & 37,2 \\
D3 & 4 & 5,1 \\
S1 & 4 & 5,1 \\
Total & 78 & 100 \\
\hline
\end{tabular}

Berdasarkan tabel 3 menunjukan bahwa masih banyak posyandu yang memiliki tingkat perkembangan pratama yaitu 28 posyandu $(35,9 \%)$, sangat berbeda jauh dengan posyandu yang memilki tingkat perkembangan mandiri yaitu hanya 4 posyandu $(5,1 \%)$.

Tabel 2.

Distribusi Frekuensi Pengetahuan, Sikap, dan Perilaku Tokoh Masyarakat mengenai Posyandu

\begin{tabular}{lcc}
\hline \multicolumn{1}{c}{ Variabel Penelitian } & N & $\%$ \\
\hline Pengetahuan Tokoh Masyarakat & & \\
Baik & 22 & 28,2 \\
Cukup & 49 & 62,8 \\
Kurang & 7 & 9,0 \\
Total & 78 & 100 \\
Sikap Tokoh Masyarakat & & \\
Positif (+) & 32 & 41,0 \\
Negatif (-) & 46 & 59,0 \\
Total & 78 & 100 \\
Perilaku Tokoh Masyarakat & & \\
Mendukung & 30 & 38,5 \\
Tidak Mendukung & 48 & 61,5 \\
$\quad$ Total & 78 & 100 \\
\hline
\end{tabular}

Tabel 3.

Distribusi Frekuensi Strata Posyandu

\begin{tabular}{lccc}
\hline \multicolumn{2}{c}{ Keberadaan Posyandu } & N & $\%$ \\
\hline Pratama & 28 & 35,9 \\
Madya & 26 & 33,3 \\
Purnama & 20 & 25,7 \\
Mandiri & & 4 & 5,1 \\
& Total & 78 & 100 \\
\hline
\end{tabular}

Tabel 4.

Hubungan Pengetahuan Tokoh Masyarakat dengan Sikap dan Perilaku Tokoh Masyarakat terhadap Posyandu

\begin{tabular}{|c|c|c|c|c|c|c|c|}
\hline \multirow{3}{*}{$\begin{array}{l}\text { Pengetahuan } \\
\text { Tokoh } \\
\text { Masyarakat }\end{array}$} & \multicolumn{4}{|c|}{ Sikap Tokoh Masyarakat } & \multirow{2}{*}{\multicolumn{2}{|c|}{ Total }} & \multirow{3}{*}{ Nilai $P$} \\
\hline & \multicolumn{2}{|c|}{ Positif } & \multicolumn{2}{|c|}{ Negatif } & & & \\
\hline & $\mathbf{N}$ & $\%$ & $\mathbf{N}$ & $\%$ & $\mathbf{N}$ & $\%$ & \\
\hline Baik & 21 & 95,5 & 1 & 4,5 & 22 & 100 & \\
\hline Cukup & 11 & 22,4 & 38 & 77,6 & 49 & 100 & 0,000 \\
\hline Kurang & 0 & 0 & 7 & 100 & 7 & 100 & \\
\hline Total & 32 & 41,0 & 46 & 59,0 & 78 & 100 & \\
\hline \multirow{3}{*}{$\begin{array}{l}\text { Pengetahuan } \\
\text { Tokoh } \\
\text { Masyarakat }\end{array}$} & \multicolumn{4}{|c|}{ Perilaku Tokoh Masyarakat } & \multirow{2}{*}{\multicolumn{2}{|c|}{ Total }} & \multirow{3}{*}{ Nilai $p$} \\
\hline & \multicolumn{2}{|c|}{ Mendukung } & \multicolumn{2}{|c|}{ Tidak Mendukung } & & & \\
\hline & $\mathbf{N}$ & $\%$ & $\mathbf{N}$ & $\%$ & $\mathbf{N}$ & $\%$ & \\
\hline Baik & 18 & 81,8 & 4 & 18,2 & 22 & 100 & \\
\hline Cukup & 12 & 24,5 & 37 & 75,5 & 49 & 100 & 0,000 \\
\hline Kurang & 0 & 0 & 7 & 100 & 7 & 100 & \\
\hline Total & 30 & 38,5 & 48 & 61,5 & 78 & 100 & \\
\hline
\end{tabular}

Berdasarkan tabel di atas, didapatkan hasil bahwa hubungan pengetahuan dengan sikap toma dan hubungan pengetahuan dengan perilaku toma memiliki nilai p 0,000. 21(95,5\%) dari 22 responden yang memiliki pengetahuan baik juga memiliki sikap yang positif, dan $7(100 \%)$ dari 7 responden yang memiliki pengetahuan yang kurang juga memiliki sikap yang negatif. $18(81,8 \%)$ dari 22 responden 
yang memiliki pengetahuan baik juga memiliki perilaku mendukung terhadap keberadaan posyandu, dan 7 responden (100\%) yang memiliki pengetahuan yang kurang juga memiliki perilaku yang tidak mendukung terhadap keberadaan posyandu.

Tabel 5.

Hubungan Sikap Tokoh Masyarakat dengan Perilaku Tokoh Masyarakat terhadap Posyandu

\begin{tabular}{|c|c|c|c|c|c|c|c|}
\hline \multirow{3}{*}{$\begin{array}{l}\text { Sikap Tokoh } \\
\text { Masyarakat }\end{array}$} & \multicolumn{4}{|c|}{ Perilaku Tokoh Masyarakat } & \multirow{2}{*}{\multicolumn{2}{|c|}{ Total }} & \multirow{3}{*}{ Nilai $p$} \\
\hline & \multicolumn{2}{|c|}{ Mendukung } & \multicolumn{2}{|c|}{$\begin{array}{c}\text { Tidak } \\
\text { Mendukung }\end{array}$} & & & \\
\hline & $\mathrm{N}$ & $\%$ & $\mathbf{N}$ & $\%$ & $\mathbf{N}$ & $\%$ & \\
\hline Positif & 27 & 84,4 & 5 & 15,6 & 32 & 100 & \\
\hline Negatif & 3 & 6,5 & 43 & 93,5 & 46 & 100 & 0,000 \\
\hline Total & 30 & 38,5 & 48 & 61,5 & 78 & 100 & \\
\hline
\end{tabular}

Berdasarkan tabel di atas, hubungan sikap dengan perilaku tokoh masyarakat terhadap posyandu memiliki nilai p 0,000. $27(84,4 \%)$ dari 32 responden yang memilki sikap positif juga memiliki perilaku mendukung terhadap keberadaan posyandu, 43 dari 46 responden yang memiliki sikap negatif juga memiliki perilaku tidak mendukung terhadap keberadaan posyandu.

Tabel 6.

Hubungan Pengetahuan, Sikap, dan Perilaku Tokoh Masyarakat dengan Strata Posyandu

\begin{tabular}{|c|c|c|c|c|c|c|c|c|c|c|c|}
\hline \multirow{3}{*}{$\begin{array}{l}\text { Pengetahuan } \\
\text { Tokoh } \\
\text { Masyarakat }\end{array}$} & \multicolumn{8}{|c|}{ Strata Posyandu } & & & \multirow{3}{*}{ Nilai $p$} \\
\hline & \multicolumn{2}{|c|}{ Pratama } & \multicolumn{2}{|c|}{ Madya } & \multicolumn{2}{|c|}{ Purnama } & \multicolumn{2}{|c|}{ Mandiri } & \multicolumn{2}{|c|}{ Total } & \\
\hline & $\mathbf{N}$ & $\%$ & $\mathbf{N}$ & $\%$ & $\mathbf{N}$ & $\%$ & $\mathbf{N}$ & $\%$ & $\mathbf{N}$ & $\%$ & \\
\hline Baik & 1 & 4,5 & 3 & 13,6 & 15 & 68,2 & 3 & 13,7 & 22 & 100 & \multirow{4}{*}{0,000} \\
\hline Cukup & 23 & 46,9 & 20 & 40,8 & 5 & 10,3 & 1 & 2,0 & 49 & 100 & \\
\hline Kurang & 4 & 57,1 & 3 & 42,9 & 0 & 0 & 0 & 0 & \multirow{2}{*}{\multicolumn{2}{|c|}{$\begin{array}{l}100 \\
100\end{array}$}} & \\
\hline Total & 28 & 35,9 & 26 & 33,3 & 20 & 25,7 & 4 & 5,1 & & & \\
\hline \multirow{3}{*}{$\begin{array}{l}\text { Sikap Tokoh } \\
\text { Masyarakat }\end{array}$} & \multicolumn{8}{|c|}{ Strata Posyandu } & \multirow{2}{*}{\multicolumn{2}{|c|}{ Total }} & \multirow{3}{*}{ Nilai $p$} \\
\hline & \multicolumn{2}{|c|}{ Pratama } & \multicolumn{2}{|c|}{ Madya } & \multicolumn{2}{|c|}{ Purnama } & \multicolumn{2}{|c|}{ Mandiri } & & & \\
\hline & $\mathbf{N}$ & $\%$ & $\mathbf{N}$ & $\%$ & $\mathbf{N}$ & $\%$ & $\mathbf{N}$ & $\%$ & $\mathbf{N}$ & $\%$ & \\
\hline Positif & 0 & 0 & 8 & 25,0 & 20 & 62,5 & 4 & 12,5 & 32 & 100 & م001 \\
\hline Negatif & 28 & 60,9 & 18 & 39,1 & 0 & 0 & 0 & 0 & 46 & 100 & 0,001 \\
\hline Total & 28 & 35,9 & 26 & 33,3 & 20 & 25,7 & 4 & 5,1 & 78 & 100 & \\
\hline Perilaku & & & & rata $F$ & syan & & & & & & \\
\hline Tokoh & & ama & & dya & & nama & & adiri & & tal & Nilai $p$ \\
\hline Masyarakat & $\mathbf{N}$ & $\%$ & $\mathbf{N}$ & $\%$ & $\mathbf{N}$ & $\%$ & $\mathbf{N}$ & $\%$ & $\mathbf{N}$ & $\%$ & \\
\hline Mendukung & 1 & 3,3 & 5 & 16,7 & 20 & 66,7 & 4 & 13,3 & 30 & 100 & \\
\hline Tidak & 27 & 56,2 & 21 & 43,8 & 0 & 0 & 0 & 0 & 48 & 100 & 0,000 \\
\hline Mendukung & & & & & & & & & & & \\
\hline Total & 28 & 35,9 & 26 & 33,3 & 20 & 25,7 & 4 & 5,1 & 78 & 100 & \\
\hline
\end{tabular}

Berdasarkan tabel diatas, didapatkan hasil hubungan pengetahuan, sikap dan perilaku tokoh masyarakat memiliki nilai $p$ 0,000. $1(4,5 \%)$ dari 22 responden yang memiliki pengetahuan baik dilihat dari strata posyandu di desanya masih pratama dan 3 responden yang memilki pengetahuan baik memiliki strata posyandu didesanya sudah mandiri. 7 responden yang memiliki pengetahuan kurang tidak memiliki strata posyandu yang sudah mandiri, tetapi terdapat 4 dari 7 responden yang memiliki pe $(13,7 \%)$ pengetahuan kurang juga memiliki strata posyandu di desanya pratama. $4(12,5 \%)$ dari 32 responden yang memiliki sikap yang positif juga memiliki strata posyandu didesanya sudah mandiri. $1(3,3 \%)$ dari 30 responden yang memiliki perilaku mendukung terhadap posyandu juga memiliki strata posyandu di desanya yang masih pratama, dan 4 $(13,3 \%)$ dari 30 responden yang memilki perilaku mendukung terhadap posyandu juga memiliki strata posyandu di desanya yang sudah mandiri. 


\section{PEMBAHASAN}

Hasil analisis data dengan menggunakan $\mathrm{Uji}$ korelasi Gamma menunjukan $p$ value $=0,000$ sehingga disimpulkan bahwa terdapat hubungan yang signifikan antara pengetahuan, sikap, dan perilaku tokoh masyarakat dengan strata posyandu.

\section{Hubungan Pengetahuan dengan Sikap Tokoh Masyarakat mengenai Strata Posyandu}

Berdasarkan tabel 4, hasil analisis data dengan menggunakan Uji Fisher Exact menunjukan $p$ value $=0,000$ sehingga disimpulkan bahwa terdapat hubungan yang signifikan antara pengetahuan dan sikap tokoh masyarakat mengenai posyandu. Terdapat $21(95,5 \%)$ dari 22 responden yang memiliki pengetahuan baik juga memiliki sikap yang positif, dan $4(57,1 \%)$ dari 7 responden yang memiliki pengetahuan yang kurang juga memiliki sikap yang negatif. Hasil tersebut sesuai dengan teori yang menyatakan bahwa individu cenderung memiliki sikap yang konformis atau searah dengan pengetahuan (Bahtiar, 2012).

Hasil penelitian ini juga sejalan dengan penelitian yang telah dilakukan oleh (Gondowardojo, 2014) menyatakan bahwa walaupun seseorang mempunyai pengetahuan yang baik atau cukup terhadap sesuatu hal, orang tersebut juga ingin mengetahui bagaimana orang lain yang berpengaruh dalam kehidupannya memandang hal tersebut karena salah satu faktor yang mempengaruhi sikap adalah pengaruh orang lain yang dianggap penting.

Pengetahuan adalah hasil tahu yang diperoleh melalui mata dan telinga. Pengetahuan merupakan hal yang penting untuk membentuk sikap dan perilaku seseorang. Sikap dan perilaku seseorang dipengaruhi oleh pengetahuan, kepercayaan, tradisi, serta ketersediaan fasilitas kesehatan dan perilaku dari petugas kesehatan (Budiman, 2013).

Tingkat pengetahuan tokoh masyarakat yang baik mengenai posyandu, dapat memengaruhi sikap positif yang diberikan tokoh masyarakat terhadap keberadaan posyandu di wilayahnya. Sikap merupakan suatu evaluasi berupa reaksi atau respon yang dibuat oleh manusia terhadap dirinya sendiri, orang lain, objek maupun issue. Sehingga sikap positif tokoh masyarakat yang diberikan merupakan suatu evaluasi berupa respon terhadap suatu objek yaitu posyandu.

Hubungan Pengetahuan dan Sikap dengan Perilaku Tokoh Masyarakat tentang Posyandu
Berdasarkan tabel 4, hasil analisis data dengan menggunakan Uji Fisher Exact menunjukan $p$ value $=0,006$ sehingga disimpulkan bahwa terdapat hubungan yang signifikan antara pengetahuan dengan perilaku tokoh masyarakat mengenai posyandu. Pada penelitian ini sampel yang diambil adalah tokoh masyarakat dari unsur RT dan RW, pemilihan sampel RT dan RW disebabkan karena RT dan RW adalah bagian dari tokoh masyarakat yang berada langsung di lingkungan masyarakat sehingga lebih dekat dengan masyarakat dan posyandu dilaksanakan di setiap wilayah RW sehingga RT dan RW merupakan pihak yang dapat memengaruhi kegiatan posyandu yang berlangsung di lingkungan masyarakat.

Hasil penelitian menunjukan bahwa 13 $(59,1 \%)$ dari 22 responden yang memiliki pengetahuan baik juga memiliki perilaku mendukung terhadap posyandu, dan $7(100 \%)$ responden yang memiliki pengetahuan yang kurang juga memiliki perilaku yang tidak mendukung terhadap strata posyandu. Hasil penelitian juga menunjukan 24 $(53,3 \%)$ dari 45 responden yang memilki sikap positif juga memiliki perilaku mendukung terhadap strata posyandu, dan $23(69,7 \%)$ dari 33 responden yang memiliki sikap negatif juga memiliki perilaku tidak mendukung terhadap posyandu.

Hasil penelitian ini sejalan dengan penelitian yang dilakukan oleh (Riza, 2015) yang menyatakan bahwa pengetahuan tokoh masyarakat memengaruhi perilaku tokoh masyarakat dalam memberdayakan masyarakat, dalam penelitian ini perilaku tokoh masyarakatnya lebih banyak yang memilki pengetahuan yang baik sehingga memengaruhi perilaku tokoh masyarakat dalam memberdayakan masyarakat. Perilaku selain dipengaruhi oleh pengetahuan juga dipengaruhi oleh sikap, karena sikap dan pengetahuan merupakan faktor predisposisi perilaku seseorang.

Berdasarkan tabel 5 , hasil analisis data dengan menggunakan chi square menunjukan $p$ value $=0,043$ sehingga disimpulkan bahwa terdapat hubungan antara sikap dengan perilaku tokoh masyarakat mengenai posyandu. Hasil penelitian menunjukan bahwa responden yang memiliki sikap positif sebagian besar memiliki perilaku yang mendukung terhadap posyandu, dan responden yang memiliki sikap negatif sebagian besar memiliki perilaku yang tidak mendukung terhadap posyandu.

Hasil penelitian ini sejalan dengan hasil penelitian yang dilakukan oleh (Akbar, 2015) bahwa tindakan mendukung tokoh masyarakat berasal dari pengetahuan yang tinggi dan sikap positif. Serta sesuai dengan hasil penelitian (Wijaya, 2014) yaitu sikap positif maupun sikap negatif memiliki pengaruh 
terhadap perilaku yang ditimbulkan oleh seseorang. Selain itu hasil penelitian ini sesuai dengan teori (Notoatmodjo, 2010) yang menyatakan bahwa pengetahuan dan sikap merupakan faktor predisposisi perilaku seseorang.

\section{Hubungan Pengetahuan, Sikap, dan Perilaku Tokoh Masyarakat dengan Strata Posyandu}

Berdasarkan hasil penelitian ini menunjukan bahwa pengetahuan, sikap, dan perilaku tokoh masyarakat saling berhubungan, yaitu pengetahuan berhubungan dengan sikap dan perilaku serta sikap berhubungan dengan perilaku. Berdasarkan teori Lawrence Green menyatakan bahwa sikap dan perilaku merupakan faktor predisposisi perilaku, sehingga pengetahuan dan sikap memengaruhi perilaku (Notoatmodjo, 2010). Berdasarkan tabel 6, hasil analisis data dengan menggunakan Uji Fisher Exact menunjukan $p$ value $=0,000$ sehingga disimpulkan bahwa terdapat hubungan yang signifikan antara pengetahuan, sikap, dan perilaku tokoh masyarakat dengan strata posyandu.

Hasil penelitian menunjukan bahwa $1(4,5 \%)$ dari 22 responden yang memiliki pengetahuan baik dilihat dari strata posyandu di desanya masih pratama dan $3(13,7 \%)$ responden yang memilki pengetahuan baik memiliki strata posyandu didesanya sudah mandiri. 7 responden yang memiliki pengetahuan kurang tidak memiliki strata posyandu yang sudah mandiri, tetapi terdapat $4(57,1 \%)$ dari 7 responden yang memiliki pengetahuan kurang juga memiliki strata posyandu di desanya pratama. Terdapat $7(15,6 \%)$ dari 45 responden yang memiliki sikap yang baik juga memiliki strata posyandu didesanya masih pratama. Dan $4(8,8 \%)$ dari 45 responden yang memiliki sikap yang baik juga memiliki strata posyandu didesanya sudah mandiri. $4(11,8 \%)$ dari 34 responden yang memiliki perilaku mendukung terhadap strata posyandu juga memiliki strata posyandu di desanya yang masih pratama, dan $3(8,8 \%)$ dari 34 responden yang memiliki perilaku mendukung terhadap strata posyandu juga memiliki strata posyandu di desanya yang sudah mandiri.

Hasil penelitian menunjukan bahwa pengetahuan, sikap dan perilaku tokoh masyarakat berhubungan yang bermakna dengan strata posyandu yang di lihat dari strata posyandunya. Hasil penelitian ini sesuai dengan (Kemenkes RI, 2011) bahwa terdapat beberapa faktor atau pihak yang memengaruhi keberadaan posyandu di lingkungan masyarakat salah satunya adalah pihak tokoh masyarakat yang berada langsung $\mathrm{di}$ lingkungan masyarakat. Tokoh masyarakat berperan dalam memberdayakan masyarakat untuk berpartisipasi dalam kegiatan posyandu, memotivasi dan membantu kader dalam mengelola posyandu serta membantu kader dalam mempersiapkan dana dan sarana dalam penyelenggaraan posyandu. Keberadaan posyandu dalam suatu desa dapat dilihat dari strata atau tingkat perkembangan posyandu, karena menurut (Kemenkes RI, 2011) menyatakan bahwa tingkat perkembangan posyandu dapat menunjukan keberdaan posyandu dapat diterima oleh lingkungan masyarakat atau tidak. Strata posyandu dilihat dari penerimaan masyarakat terhadap posyandu di lingkungannya dengan dipengaruhi oleh beberapa faktor yang diantaranya adalah tokoh masyarakat, kader, pemerintah, dan puskesmas.

Hasil penelitian ini menunjukan pengetahuan, sikap dan perilaku tokoh masyarakat terhadap posyandu saling berhubungan dan berhubungan dengan strata posyandu. Menurut (Notoatmodjo, 2010) dan (Azwar , 2016) bahwa perilaku dipengaruhi oleh pengetahuan dan sikap yang dimiliki dan perilaku merupakan suatu kegiatan individu berupa tindakan atau perbuatan yang dapat diamati. Hasil penelitian ini pun sejalan dengan hasil penelitian (Akbar , 2015) yang menyatakan bahwa tindakan tokoh masyarakat berasal dari tingkat pengetahuan dan sikap yang dimiliki. Hasil penelitian mengenai keberadaan posyandu ini sesuai dengan penelitian (Darmawan, 2015) yaitu perilaku yang diberikan tokoh masyarakat terhadap keberadaan posyandu memengaruhi perilaku masyarakat dalam ikut berpartisipasi secara langsung dalam kegiatan posyandu. Hasil penelitian (Sulaeman, 2015) menyatakan bahwa sikap tokoh masyarakat memengaruhi sikap masyarakat dalam berpartisipasi terhadap kegiatan posyandu.

\section{KESIMPULAN}

Berdasarkan hasil penelitian yang telah dilakukan terhadap 78 responden tokoh masyarakat, diperoleh hasil sebagai berikut: Responden paling banyak memiliki tingkat pengetahuan cukup terhadap keberadaan posyandu yaitu sebanyak 49 responden (62,8\%). Responden paling banyak memiliki sikap positif yaitu sebanyak 45 responden $(57,7 \%)$. Responden paling banyak memiliki perilaku yang tidak mendukung terhadap keberadaan posyandu yaitu 44 responden $(56,4 \%)$. Terdapat hubungan yang signifikan antara pengetahuan dengan sikap tokoh masyarakat mengenai keberadaan posyandu ( $p$ value $=0.000$ ), terdapat hubungan yang signifikan antara pengetahuan dengan perilaku tokoh masyarakat mengenai keberadaan posyandu ( $p$ value $=0,006$ ), dan terdapat hubungan antara sikap dengan perilaku 
tokoh masyarakat mengenai keberadaan posyandu ( $p$ value $=0,043)$. Terdapat hubungan yang signifikan antara pengetahuan, sikap, dan periaku tokoh masyarakat dengan keberadaan posyandu $(p$ value $=0.000$ ).

\section{SARAN}

Diharapkan pihak Puskesmas dapat memberikan pelatihan mengenai peran tokoh masyarakat terhadap posyandu dapat meningkatkan pengetahuan dan kesadaran tokoh masyarakat mengenai perannya terhadap posyandu. Dan diharapkan bidan desa melakukan pendekatan secara langsung kepada tokoh masyarakat untuk memberikan informasi mengenai perkembangan keberadaan posyandu dan mengajak tokoh masyarakat untuk berkontribusi langsung membantu kader dalam mengajak masyarakat untuk berpartisipasi dalam kegiatan posyandu.

\section{DAFTAR PUSTAKA}

Kementerian Kesehatan Republik Indonesia. (2014). Ayo ke Posyandu Setiap Bulan. Jakarta: Kementerian Kesehatan RI.

Kementerian Kesehatan Republik Indonesia. (2011). Pedoman Umum Pengelolaan Posyandu. Jakarta: Kementerian Kesehatan RI.

Noerjoedianto Dwi, Amir Andy, Herwansyah Nurhusna. (2014). Penguatan Kader Posyandu dalam Upaya Deteksi Dini Kesehatan Ibu, Bayi, dan Balita di Wilayah Kecamatan Telanaipura Kota Jambi Tahun 2013. Pengabdian pada Masyarakat, 29(1), 43-53.

Maternity Dainty, Putri Ratna Dewi, Aulia Devy Lestari Nurul. (2017). Asuhan Kebidanan Komunitas. Yogyakarta: Penerbit ANDI.

Sihombing Kanda, Kandarina Istiti, Sumarni. (2015). Peran Lurah, Petugas Kesehatan , dan Kader dalam Partisipasi Ibu Balita ke Posyandu di Wilayah Cakupan D/S Terendah dan Tertinggi di Kota Jambi. Jurnal Gizi dan Dietetik Indonesia, 3(2), 87-97.

Makhfudli. Efendi Ferry. (2009). Keperawatan Kesehatan Komunitas. Jakarta: Salemba Medika.

Wawan A, Dewi M. (2010). Teori dan Pengukuran Pengetahuan, Sikap, dan Perilaku Manusia. Yogyakarta: Nuha Medika.

Bahtiar Yanyan. (2012). Hubungan Pengetahuan dan Sikap Tokoh Masyarakat dengan Perannya dalam Pengendalian Demam Berdarah di Wilayah Puskesmas Kawalu Kota Tasikmalaya. Aspirator, 4(1), 73-84.
Akbar Abdillah, Gani Husni Abdul, Istiaji Edi. (2015). Dukungan Tokoh masyarakat dalam Keberlangsungan Desa Siaga di Desa Kenogo Kecamatan Gucialit Kabupaten Lumajang ejournal Pustaka Kesehatan, 3(3), 522-29.

Darmawan Kompiang Ngurah. (2015). Faktor-faktor yang memengaruhi Perilaku Kunjungan Masyarakat terhadap Pemanfaatan Pelayanan Posyandu di Desa Pemecutan Kelod Kecamatan Denpasar Barat. Jurnal Dunia Kesehatan, 5(1), 29-39.

Kementerian Kesehatan Republik Indonesia. (2013). Profil Kesehatan Indonesia Tahun 2013.

Kementerian Kesehatan Republik Indonesia. (2017). Profil Kesehatan Indonesia Tahun 2016.

Kementerian Kesehatan Republik Indonesia. (2017). Profil Kesehatan Provinsi Jawa Barat Tahun 2016. Jakarta: Kementerian Kesehatan RI.

Gondowardojo Y, Wirakusuma I. (2014). Tingkat Pengetahuan, Sikap, dan Perilaku Ibu Mengenai Pemberian Imunisasi Dasar pada Bayi di Wilayah Kerja Puskesmas Bebandem Tahun 2014. 201:10.

Budiman, Riyanto A. (2013). Kapita Selekta Kuesioner Pengetahuan dan Sikap dalam Penelitian Kesehatan. Jakarta: Salemba Medika.

Notoatmodjo. (2007). Perilaku Kesehatan dan IImu Perilaku. Jakarta: Rineka Cipta.

Azwar S. (2016). Sikap Manusia Teori dan Pengukurannya. Yogyakarta: Pustaka Pelajar.

Riza A, Atoillah M. (2015). Faktor yang Berhubungan dengan Peran Aktif Kader dalam Penjaringan Kasus Probable Difteri. Jurnal Berkala Epidemiologi, 3(1), 353-65.

Wijaya I Made Kusuma, Mestri Ni Nyoman, Trisna Gede Doddy. (2014). Pengetahuan, Sikap, dan Aktivitas Remaja SMA dalam Kesehatan Reproduksi di Kecamatan Buleleng. Jurnal Kesehatan Masyarakat, 10(1), 33-42.

Notoatmodjo. (2010). IImu Perilaku Kesehatan. Jakarta: Rineka Cipta.

Notoatmodjo S. (2010). Promosi Kesehatan Teori dan Aplikasi Jakarta: Rineka Cipta.

Saftri Millati Azka, P Priyadi Nugraha, Riyanti Emmy. (2017). Faktor-Faktor yang Berhubungan dengan Peran Kader Kesehatan dalam Pelaksanaan PHBS di Kelurahan Sarirejo Kota Semarang. Jurnal Kesehatan Masyarakat, 5(3), 594-600.

Haniek, Try Umayana, Hari Cahyati Widya. (2015). Dukungan Keluarga dan Tokoh Masyarakat 
terhadap Keaktifan Penduduk ke Posbindu Jurnal Kesehatan Masyarakat, 11(2), 96-101.

Fani Regina Chintya, Nirmala Sefita Aryuti, R Judistiani Tina Dewi. (2017), Evaluasi Kegiatan Utama Pelayanan Posyandu di Kecamatan Jatinangor. JSK, 3(1), 44-50.

Halwandi, Siziya, Magnussen, Olsen. (2013). Factor Perceived by Caretakers as Barries to Health Care for Under-Five Children in Mazabuka District, Zambia, ISRN Trop Med. 10.

Nazri Cut, Yamazaki Chico, Kameo Satomi, Herawati Dewi, Sekarwana Nanan, Raksanagara Ardini, et al. (2016). Factors Influencing Mother's Participation in Posyandu for Improving Nutritional Status of Children Under-Five in Aceh Utara District, Aceh Province, Indonesia BMC Public Health, 16(69), 1-9.
Tumbelaka Patricia, Limato Ralacia, Nasir Sudirman, Syafruddin Din, Ormel Hermen, Ahmed Rukhsana. (2018). Analisys of Indonesia's Community Health Volunteers (kader) as Maternal Health Promoters in the Community Integrated Health Service (Posyandu) Following Health Promotion Training. International Journal of Community Medicine and Public Health, 5(3), 856-63.

Sulaeman Endang Sutisna, Murti Bhisma, Waryana. (2015). Peran Kepemimpinan, Modal Sosial, Akses Informasi serta Petugas dan Fasilitator Kesehatan dalam Pemberdayaan Masyarakat Bidang Kesehatan. Jurnal Kesehatan Masyarakat Nasional, 9(4), 35361. 